\title{
A Multivariate Analysis Of Public Housing Residents: An Extension And Reply
}

\author{
James B. Kau and Charles F. Floyd*
}

We concluded in our article that public housing is helping one group of poor at the immediate cost of another group. Joseph Van Matre's comments, even though well taken, would do little to change the basic results of the paper. What follows is a discussion of the various points brought forth in the comment and an extension of the previous study.

Criticism was levied for using the word bias in conjunction with the P.H.A. (Public Housing Authority) because it connotes prejudice. Within the context of the paper it implies that the selection process was not completely random. As pointed out, there is no theoretical model to explain what criteria was used by P.H.A. in the selection process. Prejudice is only one of many selection motives. Others could be reliability of rental payment from the tenant, probability of adequate maintenance, or social compatibility with other tenants. Thus the paper avoided the question of which criterion or motive was used and instead asked the question: Were the results of the actual selection different from what would have occurred in a random process? The answer was yes, but the paper did not imply any causal relationships.

Van Matre states that the differences between the groups should be established between those selected for public housing and the actual pool of applicants rather than the potential pool. This ignores the important problem of expectations. If, for example, the potential aged applicants receive information through friends or by observation that indicates a low probability of acceptance, then they may not bother to apply. Thus, using the actual instead of the potential pool of applicants would falsely reduce the probability of measured bias.

It was noted that the means of $\mathrm{X}_{4}, \mathrm{X}_{5}$, and $\mathrm{X}_{6}$ (children under 6 , children six through eighteen, and total family size) for public housing are 1.21, 2.06, and 4.04 , respectively. Thus .77 is the mean number of household members that are not children eighteen or less. Van Matre states that since household members must be an integer value, to realize a mean of .77 indicates that several observations were zero. This is correct. The mean value includes the head-of-household; therefore .77 indicates the average number of people over 18 in the household and this number should be equal to or greater than one.

Actual sample size was 476 substandard housing dwellers and 143 public housing dwellers. Because of incomplete data this sample was reduced for the

\footnotetext{
*Assistant Professor and Professor, Department of Real Estate, The University of Georgia, Athens, Georgia.
} 
classification matrix in the original paper to 121 substandard units and 75 public housing units. Sample sizes vary with the number of included variables. This changes the proportional chance criterion slightly from .530 to .531 and the maximum chance criterion from .630 to .617 . The above minor changes in the chance criterion do not result in any reversals of the conclusions drawn in the study.

It was suggested that the similarity of certain variables, such as income, net income, per-capita income, and per-capita net income, and the empirical results indicated problems of multicollinearity. The claim for or against the existence of multicollinearity is always difficult to substantiate. The author of the comment uses reversal of signs as an indication of unstable coefficients and thus multicollinearity, neither of which necessarily provides proof. It is interesting to note that the reversal of signs did not occur with the above variables except $\mathrm{X}_{7}$, income, the mean values of which are not significantly different between the two groups. With a sample size of 196 the inclusion of 19 variables does not necessarily lead to multicollinearity.

A valid and important criticism made by Van Matre concerns the pooling of the socio-economic and characteristics-of-the-dwelling variables. Assuming no cross-correlations between the two groups, the pooling will not affect the discriminant coefficients; but the pooling does affect the percent correctly classified, thus biasing our results.

The authors have recalculated the discriminant coefficients and the classification matrix using only the socio-economic variables of the occupants. Also one income variable is used to reduce the probability of multicollinearity. The coefficients of the discriminant function are shown in Table I. As previously stated in the paper, a relative ranking of the variables is accomplished by adjusting the coefficients by multiplying each one by the standard deviation of the associated variable.

The rankings of the discriminant coefficients for the socio-economic variables indicate that number of children $<6$ is the variable that contributes most in differentiating between groups. Children 6-18 and employment are ranked 2 and 3 , respectively. Income, sex, and marital status all rank low as important discriminating variables for entry into public housing. The analysis implies that an individual has the best chance of entry into public housing if the person has children. As before the above discriminant analysis indicates, after taking into account sampling error, that the selection process is not random.

To test the discriminant power of the function, the classification matrix containing the number of correct and incorrect responses is shown in Table II. From the Mahalanobis D-statistic a multivariate F-test of the significance of the difference between two groups can be derived. The computed F-value of 4.62 indicates a significant difference between the two groups at the .05 level. The mean Zscore and standard deviation of Z-scores for the substandard housing were 0.00267 and 0.00003 , respectively. For public housing the mean $\mathrm{Z}$ was -0.00264 with a standard deviation of .00002 . Residents with Z-scores greater than zero are more likely to be substandard housing residents, and residents with Z-scores less than zero are more likely to be in public housing. 


\section{TABLE I}

COEFFICIENTS AND RELATIVE CONTRIBUTIONS SOCIO-ECONOMIC OCCUPANT CHARACTERISTICS

\begin{tabular}{lcccc}
\hline Variable & $\begin{array}{c}\text { Discriminant } \\
\text { Coefficient }\end{array}$ & $\begin{array}{c}\text { Standard } \\
\text { Deviation }\end{array}$ & $\begin{array}{c}\text { Adjusted } \\
\text { Coefficient }\end{array}$ & $\begin{array}{c}\text { Relative } \\
\text { Rank }\end{array}$ \\
\hline Age & -.00004 & 17.806 & -.00071 & 6 \\
Children & & & & \\
$\quad<6$ & -.00407 & 1.158 & -.00471 & 1 \\
$\quad 6-18$ & -.00208 & 1.718 & -.00357 & 2 \\
Total Family Size & .00071 & 2.255 & .00160 & 4 \\
Education & .00013 & 3.504 & .00046 & 7 \\
Marital Status & .00114 & .375 & .00043 & 8 \\
Employment & .00665 & .255 & .00169 & 3 \\
Sex & .00060 & .418 & .00025 & 9 \\
Race & .00269 & .316 & .00085 & 5 \\
Per Capita Income & .00000 & 339.782 & .00000 & 10 \\
\hline
\end{tabular}

\section{TABLE II}

CLASSIFICATION TABLE FOR SUBSTANDARD HOUSING RESIDENTS (GROUP 1) AND PUBLIC HOUSING RESIDENTS (GROUP 2) : SOCIO-ECONOMIC OCCUPANT CHARACTERISTICS ONLY

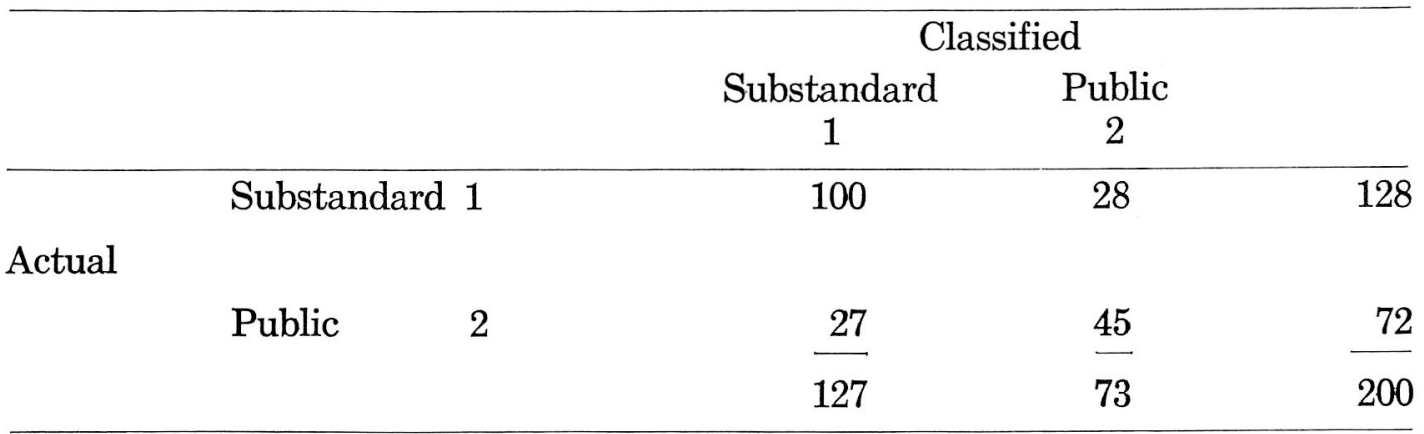

Given the biases that may result as discussed in the paper [also see Frank, Massy, and Morrison (1), Morrison (3), and Rao (4)], the results from the classification matrix for the occupant characteristics (Table II) indicate that 78.1 percent of the individuals for Group 1 are classified correctly. For Group 2, the public housing residents, 62.5 percent were correctly classified. The propor- 
tional chance criterion for the occupant group is .539. The conclusion is that the Public Housing Authority does discriminate in selecting public housing residents.

\section{SUMMARY}

Van Matre's concern over the mixing of the occupant and dwelling characteristics is valid. Reducing the number of variables and separating them resulted in less reversal of the signs and more stable coefficients. But the results were not substantially changed. The discriminant function classified 78.1 percent correctly as compared with 86.8 for the original function. The hypothesis of no significant difference was still rejected with a computed F-value of 4.62 . The separation did result in some differences in the relative rankings. Race, sex, and the age variables became less important relative to the number of children and employment. Thus the conclusion is that public housing is helping one group of poor at the immediate cost of another group, the childless poor.

\section{REFERENCES}

1. Frank, Ronald E., William F. Massy, and Donald G. Morrison. "Bias in Multiple Discriminant Analysis," Journal of Marketing Research, 2 (August 1965), pp. 250-258.

2. Kau, James B., and Charles F. Floyd. "A Multivariate Analysis of Public Housing Residents," Review of Regional Studies, Vol. 4, No. 1 (Spring 1974), pp. 42-49.

3. Morrison, Donald G. "On the Interpretation of Discriminant Analysis," Journal of Marketing Research, 6 (May 1969), pp. 156-163.

4. Rao, C. R. Linear Statistical Inference and Its Applications, John Wiley \& Sons, New York, New York. 